\title{
9-O-(Phenylcarbamoyl)quinine-bonded Carbon-Clad Zirconia for Chiral Separation of Racemic 2,4-Dinitrophenyl Amino Acids in RPLC
}

\author{
In Whan Kim, ${ }^{1}$ Sang Hyun Kwon, ${ }^{2}$ Clayton V. McNeff, ${ }^{3}$ Peter W. Carr, ${ }^{4}$ Myung Duk Jang, ${ }^{5}$ and Jung Hag Park ${ }^{2 *}$ \\ ${ }^{1}$ Department of Chemistry Education, Daegu University, Gyeongsan 712-714, Korea \\ ${ }^{2}$ Department of Chemistry, Yeungnam University, Gyeongsan 712-749, Korea. *E-mail: jhpark@yu.ac.kr \\ ${ }^{3}$ ZirChrom Separations, Inc., Anoka, MN 55303, USA \\ ${ }^{4}$ Department of Chemistry, University of Minnesota, Minneapolis, MN 55455, USA \\ ${ }^{5}$ Department of Herb Medicine, Kundong University, Andong 760-833, Korea \\ Received December 26, 2005
}

Key Words : 9-O-(Phenylcarbamoyl)quinine-bonded carbon-clad zirconia, Chiral separation, Amino acids, Reversed-phase liquid chromatography

Quinine has been widely used for enantiomer separation in HPLC as a chiral ion-pairing agent in the mobile phases and as a CSP ligand. In recent years, chiral stationary phases (CSPs) based on the use of carbamoylated derivatives of quinine and quinidine as selectors were found to be highly stereoselective for the direct resolution of chiral acids using mixtures of aqueous buffers and methanol or acetonitrile as mobile phases. ${ }^{5-7}$

Silica is the most popular choice for support of HPLC stationary phase ligands due to the mechanical strength, wide range of particle size and pore dimensions, pore structure and well-established silane chemistry. However, silica and bonded phase ligands have stability problems. Silica dissolves in mobile phase buffered at or above $\mathrm{pH} 8$ with loss of bonded phase ligand and column packing. ${ }^{8}$ Loss of organosilanes from the silica surface via hydrolysis proceeds rapidly at low $\mathrm{pH}(<3)$ and at high temperature $\left(\geq 40{ }^{\circ} \mathrm{C}\right)$. These deficiencies of the column packing create problems of poor injection reproducibility, poor peak shape, and high backpressure, thus making method development tasks difficult.

Zirconia particles are very robust material; they show no detectable signs of dissolution over the $\mathrm{pH}$ range from 1 to 14 and have been used for prolonged periods at temperatures up to $200{ }^{\circ} \mathrm{C}$ in chromatographic separations. Over the last decade, zirconia has received considerable attention as stationary phase support for HPLC. ${ }^{9,10}$ We have been working to develop efficient and chemically stable CSPs on zirconia substrate. ${ }^{11-16}$ Bare zirconia cannot be covalently modified like silica due to the instability of $\mathrm{Zr}-\mathrm{C}$ and $\mathrm{Zr}-\mathrm{O}-$ Si bonds in water. ${ }^{17}$ Zirconia-based CSPs reported have thus been prepared by coating chiral selectors on zirconia surface by utilizing Lewis acid-base chemistry.

Recently we reported chiral separation of N-(2,4-dinitrophenyl) (DNP) amino acids on a 9-O-(phenyloxycarbonyl)quinine bonded carbon-clad zirconia (QNOCZ) in reversedphase liquid chromatography (RPLC). ${ }^{18}$ Carbon-clad zirconia is made by passing organic vapors over very hot porous zirconia. ${ }^{19}$ Carbon-clad zirconia particles show similar mechanical, thermal and chemical stability to bare zirconia particles but no appreciable Lewis acidity. They do not exhibit peak tailing for amines nor do they adsorb phosphates or carboxylates. ${ }^{20}$ Although QNOCZ gave better chiral selectivity for amino acids studied than quinine-coated zirconia and quinine-bonded silica, ${ }^{21}$ synthetic yield of the chiral selector, 9-O-(4-aminophenyloxycarbonyl)quinine was very low (14\%) and bonding yield of the selector to carbon-clad zirconia was also found to be also very low due to several intermolecular site reactions of the diazonium salt of the selector. ${ }^{18}$

In this work we prepared 9-O-(phenylcarbamoyl)quininebonded carbon-clad zirconia (QNCCZ) in the hope of obtaining better synthetic and bonding yields than those for QNOCZ. It was also expected that different functionality in the linkage (carbamoyl vs. oxycarbonyl) would show different retention and selectivity behavior. QNCCZ was used as the chiral stationary phase (CSP) for separation of enantiomers of DNP-amino acids in RPLC. Retention and enantioselectivity for QNCCZ were compared to those for QNOCZ and quinine carbamate-bonded silica (QNS).

\section{Experimental Section}

Reagents and materials. All reagents used for the preparation of the stationary phase were reagent grade or better. Quinine, 4-nitrophenyl isocyanate, anhydrous pyridine, anhydrous tetrahydrofuran, diethyl ether, $\mathrm{Pd} / \mathrm{C}$, ethanol and ammonium formate were obtained from Aldrich (Milwaukee, WI, USA). D-, L- and DL-amino acids, 2,4-dinitrofluorobenzene were obtained from Sigma (St. Louis, MO, USA) or Aldrich (Milwaukee, WI, USA). N-(2,4-Dinitrophenyl) (DNP) amino acids were obtained according to the procedure described in the literature. ${ }^{22}$ HPLC-grade methanol was obtained from J.T. Baker (Phillipsburg, USA). Carbon-clad zirconia, having spherical shape, particle diameter of $5 \mu \mathrm{m}$, pore size of $30 \mathrm{~nm}$ and surface area of $30 \mathrm{~m}^{2} \mathrm{~g}^{-1}$, were obtained from ZirChrom Separations (Anoka, MN, USA). Water was processed with an Elgastat UHQ water purification system (Bucks, UK). All the chemicals were of the best quality available and used as received without any 
further purification.

Preparation of 9-O-(phenylcarbamoyl)quinine-bonded carbon-clad zirconia (QNCCZ) (QNCCZ) (Fig. 1)

9-O-(4-Nitrophenylcarbamoyl)quinine: 9-O-(4-Nitrophenylcarbamoyl)quinine was prepared according to a procedure in the literature. ${ }^{23}$ Briefly, to a solution of quinine $(2.5 \mathrm{mmol})$ in dry pyridine $(15 \mathrm{~mL})$ was added 4-nitrophenyl isocyanate $(2.75 \mathrm{mmol})$, and the solution was stirred at 80 ${ }^{\circ} \mathrm{C}$ for $3 \mathrm{~h}$. The solvent was evaporated. The resulting solid was washed with $10 \mathrm{~mL}$ of diethyl ether three times and dried in vacuum oven at $60{ }^{\circ} \mathrm{C}(73 \%$ yield $)$. Anal. Calc'd for $\mathrm{C}_{27} \mathrm{H}_{28} \mathrm{~N}_{4} \mathrm{O}_{5}$ : C, 66.38; H, 5.78, N, 11.47. Found: C, 65.97; $\mathrm{H}, 5.91, \mathrm{~N}, 11.27$. IR $\left(\mathrm{cm}^{-1}\right)(\mathrm{KBr}): 3319,2920,2364,1596$, 1508, 1342, 1215, 1176, 1103. ${ }^{1} \mathrm{H}-\mathrm{NMR}$ (ppm) (300 MHz, $\mathrm{d}_{6}$-DMSO): $8.61(\mathrm{~d}, 1 \mathrm{H}), 8.14(\mathrm{~d}, 2 \mathrm{H}), 7.99(\mathrm{~d}, 2 \mathrm{H}), 7.92(\mathrm{~d}$, 2H), $7.26(\mathrm{~d}, 1 \mathrm{H}), 7.04(\mathrm{~s}, 2 \mathrm{H}), 5.75(\mathrm{~m}, 1 \mathrm{H}), 5.42(\mathrm{~d}, 1 \mathrm{H})$, $5.00(\mathrm{~d}, 2 \mathrm{H}), 3.75$ (s, 3H), $3.27(\mathrm{~m}, 1 \mathrm{H}), 2.20(\mathrm{~m}, 5 \mathrm{H}), 1.14$ $(\mathrm{m}, 5 \mathrm{H})$.

9-O-(4-Aminophenylcarbamoyl)quinine: 9-O-(4-Aminophenylcarbamoyl)quinine was prepared by reducing 9-O-(4nitrophenylcarbamoyl)quinine according to a procedure in the literature. ${ }^{23}$ Briefly, $\mathrm{Pd} / \mathrm{C}(303 \mathrm{mg})$ and ammonium formate $(3.28 \mathrm{~g})$ were added under nitrogen at room temperature to a solution of 9-O-(4-nitrophenylcarbamoyl)quinine $(890 \mathrm{mg})$ in dry THF $(10 \mathrm{~mL})$. After $3 \mathrm{~h}$ the reaction mixture was filtered and the solvent was evaporated. To eliminate ammonium formate, the residue was dried overnight at 0.01 torr and $30{ }^{\circ} \mathrm{C}$ ( $45 \%$ yield). Anal. Calc'd for $\mathrm{C}_{27} \mathrm{H}_{30} \mathrm{~N}_{4} \mathrm{O}_{3}: \mathrm{C}$, 70.72; H, 6.59, N, 12.22. Found: C, 70.01; H, 6.29, N, 11.81 . IR $\left(\mathrm{cm}^{-1}\right)(\mathrm{KBr}): 3355,2937,2360,1596,1508,1330,1228$, 1176, 1110. ${ }^{1} \mathrm{H}-\mathrm{NMR}$ (ppm) (300 MHz, d $\mathrm{d}_{6}$-DMSO): 8.60 (d, $1 \mathrm{H}), 8.04(\mathrm{~d}, 2 \mathrm{H}), 7.42(\mathrm{~d}, 2 \mathrm{H}), 7.28(\mathrm{~d}, 1 \mathrm{H}), 7.08(\mathrm{~d}, 2 \mathrm{H})$, $6.41(\mathrm{~d}, 2 \mathrm{H}), 5.71(\mathrm{~m}, 1 \mathrm{H}), 5.47(\mathrm{~d}, 1 \mathrm{H}), 5.03(\mathrm{~d}, 2 \mathrm{H}), 3.94$ (s, 2H), 3.75 (s, 3H), 3.22 (m, 1H), $2.17(\mathrm{~m}, 5 \mathrm{H}), 1.47$ (m, 5H).

9-O-(Phenylcarbamoyl)quinine-bonded carbon-clad zirconia: 9-O-(Phenylcarbamoyl)quinine-bonded carbonclad zirconia was prepared according to a modified method of the procedure in the literature. ${ }^{24}$ Briefly, one gram of carbon-clad zirconia was added to a solution of $4.58 \mathrm{~g}$ of 9$\mathrm{O}-(4$-aminophenylcarbamoyl)quinine dissolved in $83 \mathrm{~g}$ of water. The resulting suspension was cooled to $30{ }^{\circ} \mathrm{C}$ and $0.70 \mathrm{~g}$ of concentrated nitric acid was added. An aqueous solution containing $0.70 \mathrm{~g}$ of sodium nitrite was then added gradually with stirring, forming 9-O-(phenylcarbamoyl)quinine diazonium hydroxide inner salt in situ, which reacts with the carbon on zirconia. The resulting product, 9-O(phenylcarbamoyl)quinine-bonded carbon-clad zirconia, was filtered, washed three times each with water, ethanol and acetone, and dried in an oven at $125^{\circ} \mathrm{C}$. Chiral selector density based on the percent nitrogen from microanalysis was found to be $2.02 \mathrm{mmol} \mathrm{m}^{-2}$.

Chromatography: The same packing conditions were employed for packing all three packing materials. Packing materials were suspended in a $(1: 1)$ hexane/2-propanol mixture and packed into $15 \mathrm{~cm} \times 1 \mathrm{~mm}$ (ID) columns using the downward slurry method at $c a .7000$ psi. 2-Propanol was employed as the displacing solvent. A chromatographic system consisting of a Rheodyne Model 7520 injector with a 0.5- $\mu$ L internal loop (Rohnert Park, CA, USA), a Model 530 column oven (Alltech, IL, USA) set at $30{ }^{\circ} \mathrm{C}$ and a Linear Model 200 UV/VIS detector (Alltech, IL, USA) with a 0.25$\mu \mathrm{L}$ flowcell set at $254 \mathrm{~nm}$ was used. A Hewlett-Packard Series 3365 integrating recorder (Avondale, CA, USA) was used to measure the retention time $\left(t_{R}\right)$ and to record chromatograms. The mobile phase was $90: 10(\mathrm{v} / \mathrm{v} \%)$ of methanol-ammonium acetate buffer $(p \mathrm{H} 4.5,0.1 \mathrm{M})$. They were filtered through a membrane filter of $0.5-\mu \mathrm{m}$ pore size and degassed prior to use. The flow rate was $100 \mu \mathrm{L} \mathrm{min}{ }^{-1}$. Deuterated water was used as the dead time $\left(\mathrm{t}_{\mathrm{o}}\right)$ marker by noting the baseline disturbance due to the refractive index difference. Peak identification was carried out by injecting solutions of each enantiomer of amino acids.

\section{Results and Discussion}

Retention factors for the early eluting enantiomers $\left(\mathrm{k}_{1}\right)$ and selectivity factors $(\alpha)$ for fourteen DNP-amino acids in $90: 10(\mathrm{v} / \mathrm{v} \%)$ methanol-acetate buffer $(p \mathrm{H} 4.5,0.1 \mathrm{M})$ are listed in Table 1. The plate number of the QNCCZ and QNOCZ columns for the unretained marker was 1116 and 950, respectively. Quinine bonding density based on the percent nitrogen from microanalysis was found to be 2.02 and $1.87 \mathrm{mmol} \mathrm{m}^{-2}$, respectively. A bar graph is shown for facile comparison of retention and chiral selectivity data (Fig. 2).

For most DNP-amino acids retention and selectivity are longer on QNCCZ than on QNOCZ. The longer retention on QNCCZ is believed to be due to the higher bonding density of QNCCZ but the extent of retention increase is too large to

Table 1. Separation data for DNP-amino acids on QNCCZ, $\mathrm{QNOCZ}$ and $\mathrm{QNS}^{a}$

\begin{tabular}{|c|c|c|c|c|c|c|}
\hline \multirow{2}{*}{$\begin{array}{l}\text { Amino } \\
\text { acids }\end{array}$} & \multicolumn{2}{|c|}{ QNCCZ } & \multicolumn{2}{|c|}{$\mathrm{QNOCZ}^{b}$} & \multicolumn{2}{|c|}{$\mathrm{QNS}^{b}$} \\
\hline & $k_{1}^{c}$ & $\alpha^{d}$ & $k_{1}$ & $\alpha$ & $k_{1}$ & $\alpha$ \\
\hline Ala & 15.84 & 1.00 & 5.26 & 1.03 & 1.29 & 1.33 \\
\hline Val & 19.44 & 2.22 & 1.68 & 1.01 & 0.91 & 1.53 \\
\hline Leu & 16.81 & 4.67 & 2.14 & 1.19 & 0.84 & 1.58 \\
\hline Ileu & 15.96 & 3.60 & 3.03 & 1.02 & 0.80 & 1.73 \\
\hline Pro & 15.84 & 2.12 & 1.81 & 1.52 & 1.11 & 1.22 \\
\hline Met & 18.48 & 1.02 & 6.70 & 1.01 & 1.10 & 1.34 \\
\hline $\mathrm{PhG}$ & 12.14 & 1.24 & 5.07 & 1.22 & 0.84 & 1.83 \\
\hline Phe & 13.18 & 1.40 & 5.83 & 1.10 & 1.27 & 1.29 \\
\hline Thr & 16.29 & 1.01 & 2.01 & 1.04 & 0.91 & 1.80 \\
\hline Tyr & 14.92 & 1.32 & 8.95 & 1.05 & 1.43 & 1.30 \\
\hline Asn & 16.54 & 1.12 & 7.61 & 1.00 & 1.46 & 1.41 \\
\hline Gln & 16.82 & 1.05 & 4.81 & 1.06 & 1.35 & 1.22 \\
\hline His & 15.42 & 1.74 & 14.44 & 1.17 & 1.52 & 1.34 \\
\hline Trp & 13.82 & 1.33 & 13.15 & 1.31 & 1.87 & 1.60 \\
\hline
\end{tabular}

${ }^{a}$ Mobile phase, $90: 10$ methanol-ammonium acetate buffer $(0.1 \mathrm{M}, p \mathrm{H}$ 4.5). QNCCZ: particle size, $5 \mu \mathrm{m}$; plate number $\mathrm{N}$ (unretained marker), 1116; bonding density, $2.02 \mu \mathrm{mol} / \mathrm{m}^{2}$. QNOCZ: particle size, $5 \mu \mathrm{m} ; \mathrm{N}$, 950; bonding density, $1.87 \mu \mathrm{mol} / \mathrm{m}^{2}$. QNS: particle size, $5 \mu \mathrm{m} ; \mathrm{N}, 1036$; bonding density, $2.00 \mu \mathrm{mol} / \mathrm{m}^{2}$. ${ }^{b}$ Chromatographic data from ref. 18 . ${ }^{c}$ Retention factor for the first-eluting enantiomer, $k=\left(t_{\mathrm{R}}-t_{\mathrm{o}}\right) / t_{\mathrm{o}}$. ${ }^{d}$ Selectivity factor, $\alpha=k_{2} / k_{1}$. 
<smiles>C=CC1CN2CCC1C([C@H](O)c1ccnc3ccc(OC)cc13)C2</smiles><smiles>C=CC1CN2CCC1C2[C@H](OC(=O)Nc1ccc([N+](=O)[O-])cc1)c1ccnc2ccc(OC)cc12</smiles>

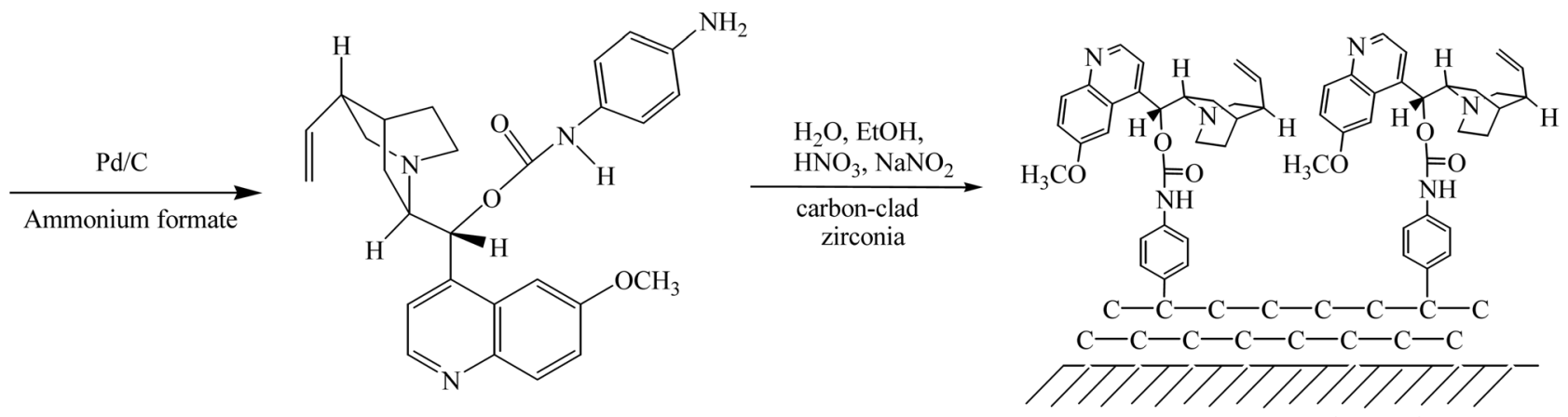

carbon-clad zirconia

Figure 1. Reaction scheme for the preparation of 9-O-(phenylcarbamoyl)quinine-bonded carbon-clad zirconia.
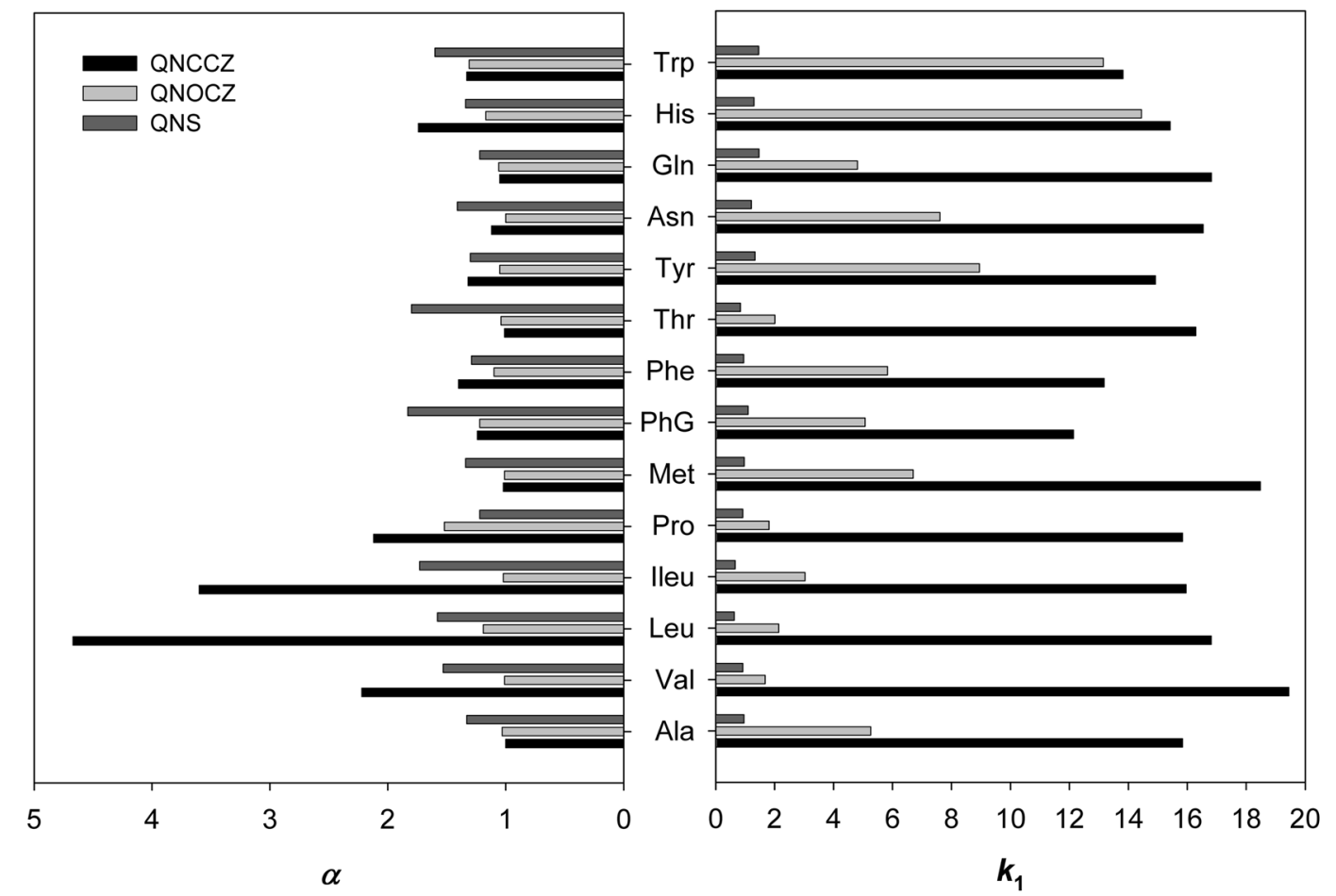

Figure 2. Retention and selectivity factors of DNP amino acids on QNCCZ, QNOCZ and QNS. Mobile phase, 90 : 10 methanol-ammonium acetate buffer $(0.1 \mathrm{M}, p \mathrm{H} 4.5)$.

be rationalized solely by the greater bonding density on QNCCZ. We do not have a clear explanation for why QNCCZ CSP shows much higher retention than QNOCZ. One plausible explanation is as follows: The N-H hydrogen of the carbamate tether on QNCCZ, which is not present on
QNOCZ, may undergo extra hydrogen bonding (HB) interaction with any hydrogen bond-accepting moiety of a DNP-amino acid molecule, thereby increasing retention. This extra HB interaction might also increase stereodiscriminating potential of QNCCZ and thus show better 
enantioselectivity. The selectivity factors for most amino acids investigated were indeed higher on QNCCZ than on QNOCZ as seen in Figure 2. The importance of strong HB between the N-H hydrogen of the carbamate group and the carbonyl function of amino acid derivatives in chiral discrimination has been shown for chiral separation of 2,4dinitrobenzoyl amino acids on quinine carbamate-bonded silica CSPs. ${ }^{5}$ For aliphatic amino acids such as Val, Leu, ILeu and Pro both retention and selectivity are much higher on QNCCZ than on QNOCZ. For the remaining amino acids retention is still higher on QNCCZ while chiral selectivities are only a little better than or comparable to those on QNOCZ.

The stability of the QNCCZ columns was checked by measuring retention factor of the first eluting enantiomer of DNP-Pro after passage of every 500 column volume of the eluent through the column. After 6,000 column volumes only less than $2 \%$ decrease in retention factor of the test solute was observed.

For all DNP-amino acids retention is much longer on QNCCZ than on QNS even if the bonding density of QNCCZ is about the same as that for QNS. The retention factor values on QNS are smaller than 2 for all amino acids but those on QNCCZ are all greater than 12. The much longer retention on the zirconia CSP is likely due to strong, non-stereodiscriminating (dispersive and dipole-induced dipole type) interactions of the analyte molecules with the carbon layer on the carbon-clad zirconia. The presence of the phenyl group in the tether on QNCCZ instead of the propyl group in QNS might also contribute to increased retention on QNCCZ.

While retention is much longer on QNCCZ chiral discrimination ability is not very good. Selectivity factors for aliphatic amino acids such as Val, Leu, Ileu and Pro are greater on QNCCZ than on QNS but for the remaining amino acids they are only slightly better (Tyr and His) or worse than those on QNS. On chiral stationary phases prepared by immobilizing chiral selector ligands with localized chiral centers enantioselective interactions are much rarer than non-enantioselective interactions. ${ }^{25}$ Chiral separations on these CSPs can be achieved only when enantioselective interactions are strong and some strict conditions regarding the relative orientation between the enantioselective group and the analyte molecule, such as the three-point complex interactions, are satisfied. Strong, chiral indiscriminating dispersive and induction interactions between the carbon layer on the zirconia surface and the analyte molecule simply prolong the retention and are very likely to cause geometrical constraints required by chiral recognition not to be well satisfied, thus in turn giving diminished chiral selectivity.

In summary, although synthetic and bonding yields for 9O-(phenylcarbamoyl)quinine-bonded carbon-clad zirconia were better than those for QNOCZ and enantioselectivity for the amino acids studied was better than QNOCZ, QNCCZ exhibited much longer retention than QNOCZ and QNS. It is believed that more studies are required to optimize separation on this CSP by employing different bonding chemistry for the CSP and separation conditions that reduces retention while improving chiral selectivity. Work is in progress to this end.

Acknowledgments. This work was supported in part by a grant (C00140) from the Korea Research Foundation and in part by a grant (R01-2006-000-10004-0) from the Korea Science and Engineering Foundation. IWK acknowledges a financial support from the Daegu University (2004).

\section{References}

1. Pettersson, C. J. Chromatogr. 1984, 316, 553.

2. Pettersson, C.; Schill, G. J. Liq. Chromatogr. 1986, 9, 269.

3. Rosini, C.; Altemura, P.; Pini, P.; Bertucci, C.; Zullino, G.; Salvadori, P. J. Chromatogr. 1985, 348, 79.

4. Salvadori, P.; Rosini, C.; Pini, D.; Bertucci, C.; Uccello-Barretta, G. Chirality 1989, 1, 161

5. Lämmerhofer, M.; Lindner, W. J. Chromatogr. A 1996, 741, 33.

6. Lämmerhofer, M.; Maier, N. M.; Lindner, W. Am. Lab. 1998, 30, 71

7. Piette, V.; Lämmerhofer, M.; Lindner, W.; Crommen, J. J. Chromatogr. A 2003, 987, 421.

8. Kirkland, J. J.; van Straten, M. A.; Claessans, H. A. J. Chromatogr. A 1995, 691, 3 .

9. Nawrocki, J.; Dunlap, C. J.; Carr, P. W.; Blackwell, J. A. Biotechnol. Prog. 1994, 10, 561.

10. Jackson, P. T.; Carr, P. W. Chemtech Oct. 29, 1998, 29.

11. Castells, C. B.; Carr, P. W. Anal. Chem. 1999, 71, 3013.

12. Park, J. H.; Ryu, J. K.; Park, J. K.; McNeff, C. V.; Carr, P. W. Chromatographia 2001, 53, 405.

13. Park, S. Y.; Park, J. K.; Park, J. H.; McNeff, C. V.; Carr, P. W. Microchem. J. 2001, 70, 179.

14. Park, J. H.; Whang, Y. C.; Jung, Y. J.; Okamoto, Y.; Yamamoto, C.; Carr, P. W.; McNeff, C. V. J. Sep. Sci. 2003, 26, 1331.

15. Kim, I. W.; Okamoto, Y.; Carr, P. W.; Ryu, J. K.; Park, J. H. Bull. Korean Chem. Soc. 2002, 23, 1014.

16. Kim, I. W.; Ryu, J. K.; Ahn, S. D.; Park, J. H.; Lee, K.-P.; Ryoo, J. J.; Hyun, M. H.; Okamoto, Y.; Yamamoto, C.; Carr, P. W. Bull. Korean Chem. Soc. 2003, 24, 239.

17. Nawrocki, J.; Rigney, M. P.; McCormick, A.; Carr, P. W. J. Chromatogr. A 1993, 657, 299.

18. Park, J. H.; Lee, J. W.; Kwon, S. H.; Cha, J. S.; Carr, P. W.; McNeff, C. V. J. Chromatogr. A 2004, 1050, 151.

19. Weber, T. P.; Carr, P. W.; Funkenbush, E. F. J. Chromatogr. 1990, 519, 31 .

20. Rigney, M. P.; Weber, T. P.; Carr, P. W. J. Chromatogr. 1989, 484, 273.

21. Park, J. H.; Lee, J. W.; Song, Y. T.; Ra, C. S.; Cha, J. S.; Ryoo, J. J.; Lee, W.; Kim, I. W.; Jang, M. D. J. Sep. Sci. 2004, 27, 977.

22. Lawrence, J. F.; Frei, R. W. Chemical Derivatization in Liquid Chromatography; Elsevier: New York, 1976.

23. Sabbioni, G.; Hartley, R.; Schneider, S. Chem. Res. Toxicol. 2001, 14,1573 .

24. Belmont, J. A. US Patent, 5,672,198, 1997

25. Fornstedt, T.; Sajonz, P.; Guiochon, G. Chirality 1998, 10, 375. 